\title{
Acute coronary syndrome by two different spontaneous coronary artery dissection types in two different vessels
}

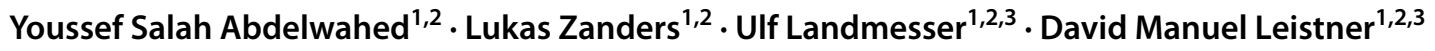

Received: 15 February 2021 / Accepted: 7 May 2021 / Published online: 11 May 2021

(c) The Author(s) 2021

\begin{abstract}
A 48-year-old, otherwise healthy woman, with a new onset recurring chest pain over a period of 1 week was admitted for coronary angiography. Surprisingly, a tubular-shaped high-grade stenosis in the middle segment of the LAD (Fig. 1a and Video 1) was revealed, simultaneous with a clear dissection seen as a radiolucent lumen resembling a Type 1 spontaneous artery dissection (SCAD), extending from the middle part of the RCA to its distal segment (Fig. 2a). Filling of the distal part of the RCA through contralateral LAD collaterals as well as TIMI II flow at LAD, led to primary imaging-guided PCI of the LAD. Optical coherence tomography imaging (OCT) showed a dissection flap and concomitant intramural hematoma (Fig. 1b) attributing to Type 3 SCAD, which was treated by primary drug-eluting-stent implantation (Fig. 1c). During a follow-up appointment after 6 weeks, the patient still reported about recurring chest pain since the first intervention. Thus, staged
\end{abstract}

PCI of the RCA was performed: the proximal dissected segment was crossed into the side branch using microcatheter support, followed by exchange to a double-lumen microcatheter, allowing the safe crossing to the distal RCA lumen by a Gaia-1 wire (after failed crossing using a floppy and then a Fielder XT-A wires) (Fig. 2 b and Video 2). Long-segment drug-eluting-stent PCI was performed covering the dissected part completely (Fig. 2c).

SCAD is now known to be an important cause of myocardial infarction in young patients [1]. Although SCAD still considered as uncommon, awareness of both the disease as well as the definition of its pathophysiologic mechanisms were approved by intracoronary high-resolution OCT imaging recently $(1,2)$. Here, we present a rare case, in which simultaneously two different forms - representing both rare subtypes of SCAD_could be detected and successfully treated in two different vessels in the same patient.

David Manuel Leistner

david-manuel.leistner@charite.de

1 Department of Cardiology, Charité-Universitätsmedizin Berlin, Campus Benjamin Franklin, Hindenburgdamm 30, 12203 Berlin, Germany

2 DZHK (German Centre for Cardiovascular Research), Partner site Berlin, Berlin, Germany

3 Berlin Institute of Health (BIH), Berlin, Deutschland 

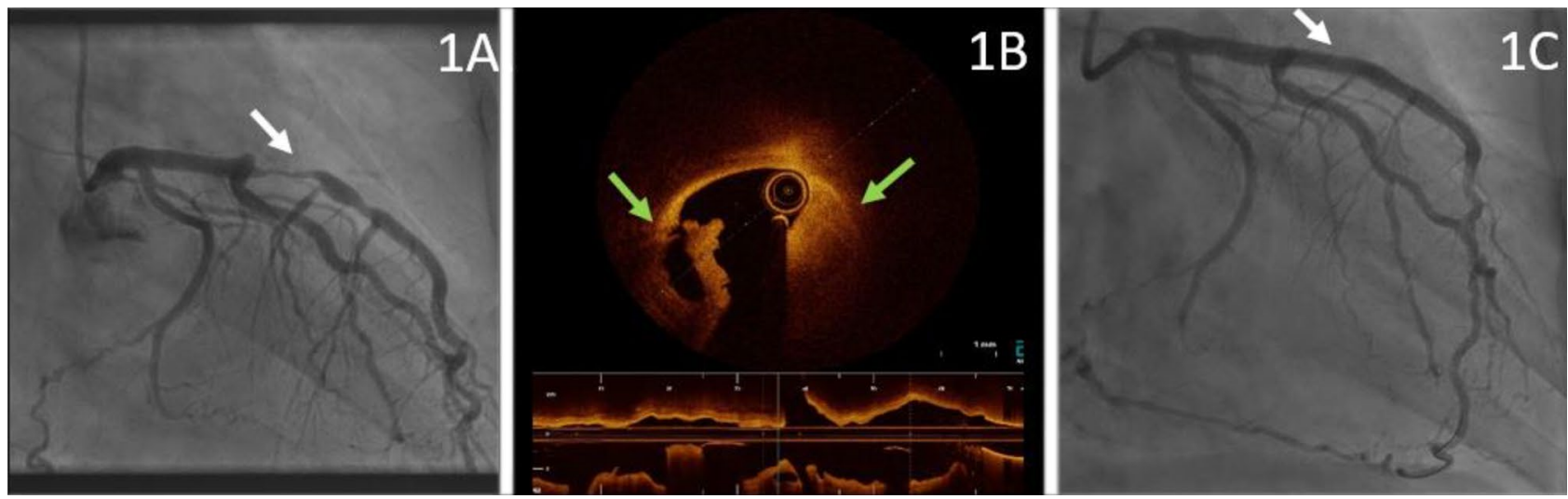

Fig. 1 a Tubular high-grade stenosis in the middle part of the LAD (White Arrow). b OCT revealed dissection flap and intramural hema- toma (Green Arrows) according SCAD Type 3, which was covered by consecutive DES-PCI (white arrow; c)
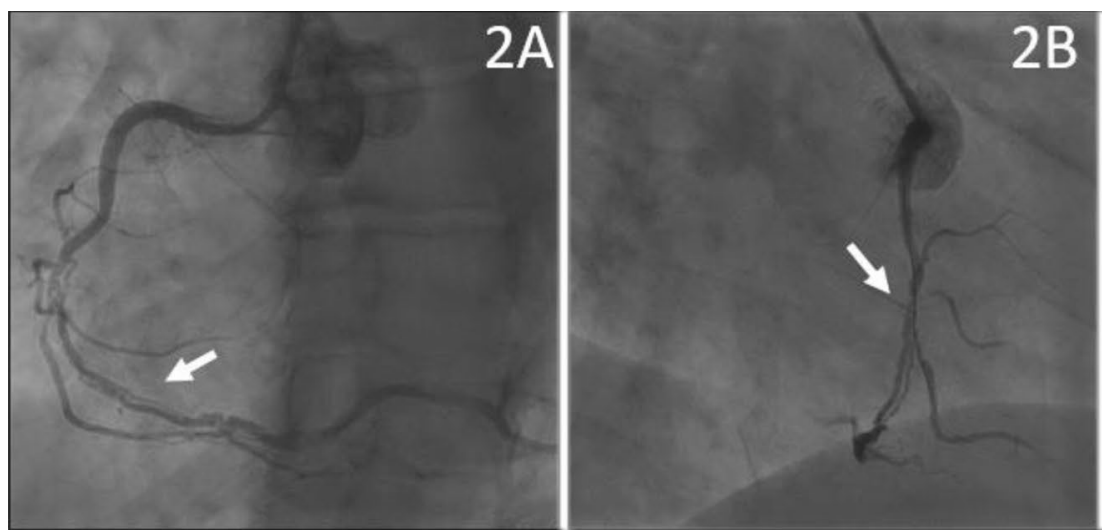

Fig. 2 a RCA with radiolucent dissected lumen starting from its middle part (white arrow) according SCAD Type 1. b Crossing point of the wire into the true lumen of the RCA over the side branch using

Supplementary Information The online version contains supplementary material available at https://doi.org/10.1007/s12928-021-00783-6.

Funding Open Access funding enabled and organized by Projekt DEAL. No research funding regarding this paper. All authors report no disclosures.

Open Access This article is licensed under a Creative Commons Attribution 4.0 International License, which permits use, sharing, adaptation, distribution and reproduction in any medium or format, as long as you give appropriate credit to the original author(s) and the source, provide a link to the Creative Commons licence, and indicate if changes were made. The images or other third party material in this article are included in the article's Creative Commons licence, unless indicated otherwise in a credit line to the material. If material is not included in the article's Creative Commons licence and your intended use is not permitted by statutory regulation or exceeds the permitted use, you will need to obtain permission directly from the copyright holder. To view a copy of this licence, visit http://creativecommons.org/licenses/by/4.0/. double-lumen microcatheter support (white arrow) with subsequent successful DES-PCI (c)

\section{References}

1. Hayes SN, Kim ESH, Saw J, et al. Spontaneous coronary artery dissection: current state of the science: a scientific statement from the American heart association. Circulation. 2018;137(19):e52357. https://doi.org/10.1161/CIR.0000000000000564.

2. Saw J, Mancini GBJ, Humphries KH. Contemporary review on spontaneous coronary artery dissection. J Am Coll Cardiol. 2016;68(3):297-312. https://doi.org/10.1016/j.jacc.2016.05.034 (Erratum in: J Am Coll Cardiol. 2016 Oct 4; 68 (14): 1606 PMID: 27417009).

Publisher's Note Springer Nature remains neutral with regard to jurisdictional claims in published maps and institutional affiliations. 